FOLIA SCANDINAVICA VOL. 20 POZNAŃ 2016 DOI: $10.1515 / \mathrm{fsp}-2016-0043$

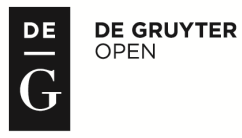

PRESSTO.

\title{
ER $\emptyset K O$ ET KONFIKS ELLER ER DET IGEN BLEVET TIL EN ROD?
}

\author{
ANDRZEJ SZUBERT \\ Adam Mickiewicz University in Poznań
}

ABSTRACT. The term Fr. confixe is not new and was used for the first time in 1982 but at present it is actually only used in German language linguistic literature. Confixes are morphemes of Latin and Greek origin that can form words with stems, affixes and other confixes. The article is an attempt at describing the confix $\phi k o$ - in the Danish language as well as its semantic and morphological properties. The status of confixes is unusual because they are actually bound morphemes with the exception that two confixes can form a word. The use of $\phi k o$ - shows that it is on the way to becoming a free morpheme (root), or perhaps it has become it already.

\section{INDLEDNING}

Morfemet $\phi k o$ stammer fra gr. oikos = 'hus, husholdning, ' og det klassificeres tit som en konfiks, selv om det i oldgræsk var en stamme, altså et frit morfem. Konfikser hører ikke til hovedbyggeklodser i orddannelsen. Der er skrevet en del om denne problematik, og forskerne er langt fra at være enige om, hvordan konfikser skal defineres. Artiklen skal hverken betragtes som en udtømmende redegørelse eller definition af termen eller give et afgørende svar på, hvad $\phi k o$ skal betragtes som. I det følgende vil jeg kun kort referere til nogle lingvisters syn på termen og selv kommentere dem. Jeg vil her ikke gå meget dybt ind på diskussionen om konfiksers definition, og bl.a. forskellen mellem et konfiks og et affiksoid, men med udgangspunkt $i$ eksisterende terminologi prøve at fremlægge oprindelsen og brugen af $\phi k o-$, der af Rajnik (2013) betragtes som et prækonfiks.

\section{OM TERMINOLOGIEN}

Betegnelsen konfiks anvendes for første gang i dansksproget lingvistisk litteratur af Rajnik (2014), selv om fænomenet er kendt fra flere tidligere arbejder, som f.eks. hos Jarvad (1995). Begrebet fr. confixe blev for første 
gang brugt af Kocourek (1982), og overtaget af Schmidt (1987) som ty. Konfix. Efter hans mening var et Konfix ikke "wortfähig", men den var "baseog kompositionsgliedfähig". Dette tyder på, at et konfiks kunne være en stamme (som kompositionsled, eller base i derivater), men kunne ikke forekomme som et selvstændigt ord.

For Fleischer/Barz (1995:67 f.) er Konfixe ikke selvstændige rødder, men de kan optræde som første og andet led i komposita med andre stammer, eller hvor konfikser kan udgøre første og andetled i Konfixkomposita. De kan også bruges som baser til Konfixderivater. Som Konfixkomposita nævner de tre strukturtyper:

- Konfix als Erstglied + Substantiv: Aerobus, -medizin, Bioblock, -gas [...].

Konfix als Zweitglied, kombiniert mit einer wortfähigen Erstkonstituente [...]:

Auto-, Motodrom, [...], Kosmodrom, Phonothek, Psychologie, Techokrat(ie).

Konfix als Erst- und Konfix als Zweitglied: Astronaut, Aquanaut [...]. (ibid.)

Eisenberg (2004:244) betragter et konfiks som "gebundene morphplogische Einheit, die nicht allgemein als Derivationsbasis dient, sondern auf das Vorkommen in Konfixkomposita spezialisiert ist". Hos de ovennævnte forfattere indgår konfikser i Konfixkomposita.

For Donalies (1999:200) er de "basisfähig", men ikke "kompositionsfähig".

Neef (2009:399) nævner Konfixkomposita og mener, at

These neoclassical compounds (German Konfixkomposita) differ from typical compounds in that at least one of the basic elements is a bound form. These bound forms, however, differ from affixes in certain respects like appearing in both first and second position of a word or in combining with each other to form a whole word (cf. Elsen 2005, Schu 2005). Linguists are not unanimous as to whether this type of productive lexeme formation belongs to either compounding or derivation or forms a main type of its own.

Neoclassical compounds nævnes også bl.a. hos Scalise/Lisetto (2009:47):

[...] neoclassical compounds - which concern those particular entities called "semiwords" (sW) (Scalise 1984) - are generally encompassed in the subordinate class, albeit with some exceptions. The use of the neoclassical label therefore is only a means for describing the kind of constituent that is used.

som angiver eksempler på strukturmuligheder $\mathrm{sW}+\mathrm{sW}, \mathrm{sW}+\mathrm{N}, \mathrm{N}+\mathrm{sW}$. Der nævnes ikke muligheden for at bruge konfikserne som baser i derivater, men teksten handler om komposita.

Hos Bauer (1988:38, 90 ff.) finder man en beskrivelse af neo-classical compouds, hvor han bl.a. siger, at "neo-classical compounding is like blending because both involve the fusion of two elements neither of which is potentially 
free, occasionally to the extent that one is indistiguishable from the other". Han påpeger egenskaben "potentially free", hvilket betyder, at de ikke betragtes som fri morfemer.

Hos W. Müller (1989; efter Skolseg, 1997:66) forekommer termen Konfix, og betegner orddannelseselementer af græsk evt. latinsk herkomst. De kan i modsætning til affikser forekomme med andre konfikser og også som en selvstændig enhed.

Rajnik (2014:45) mener, at "[...] subkonfikser bør opfattes som orddannelseselementer af latinsk eller græsk oprindelse [...], der ikke kan forekomme som frie morfemer. De kan indgå i større orddannelsesstrukturer med en stamme, et præfiks eller med et andet subkonfiks".

Schindler (1997:537) mener: "Ing. Komposition ist Stammkomposition". Jeg tilslutter mig dette synspunkt og synes, at man måske kunne overveje, om man ikke burde foreslå at udskifte ordet komposita med noget andet, som f.eks. konfiksdannelser (ty. Konfixbildungen), fordi det kan være misledende, hvis man antager, at komposita består af stammer (der indeholder mindst en rod), og konfikser er ikke "orddannende", i hvert fald ifølge mange forskere. Dette er lidt forvirrende, fordi derivater har deres udgangspunkt i stammer (også kaldt baser) og komposita består af stammer, der tit indeholder bindebogstaver (jf. Szubert, 2012).

Den mest detaljerede og omfattende beskrivelse af fænomenet inden for den skandinaviske forskning findes hos Jarvad (1995:209 ff.), hvor hun skelner mellem fire kategorier. Det er frie rødder (f.eks. hest, rock) "dvs. rødder som har en fast betydning [...], som kan stå alene, og som kan indgå i orddannelsen", bundne rødder, som hun kalder for kryptorødder (f.eks. bio- eller -pat) "dvs. rødder som har en betydning af samme faste karakter som en fri rod, og som er bundet til et andet element der gør at de to til sammen udgør et leksem". Hun nævner, at de over en tid kan blive til frie rødder, hvilket jeg synes er vigtigt at nævne. Den næste kategori er frie affikser "dvs. affikser som er stærkt produktive, som har en billedlig, indskrænket, degenereret eller vagere betydning end når det optræder som en fri rod, og betydningen angiver en retning eller tendens til det som leksemet betyder.". Hun kalder dem for skabsaffikser. Den sidste gruppe udgør bundne affikser "dvs. affikser som har en ukonkret betydning, som angiver en retning eller tendens til den betydning som leksemet har, og som ikke kan optræde uden en rod". Hun ser på de fire kategorier under hensyntagen af både den historiske udvikling, tryk og semantik. Af andre skandinaviske forskere kan nævnes Høy (1999:53 ff.), som for en art rødder betragter morfemer, der ikke forholder sig som affikser, og nævner kryptorødder og hybridafledninger.

En grundig gennemgang af tysksproget forskning til emnet findes hos Elsen (2005). Hun diskuterer også kriterier for klassificeringen af de pågældende morfemer som konfikser eller f.eks. affiksoider, som hun skelner fra hinanden. Med dette 
synspunkt er jeg helt enig, for jeg synes, at man i de to sidste tilfælde har med to forskellige historiske processer at gøre. Dette er ikke stedet for en terminologisk diskussion, men jeg vil kun nævne to træk, som viser skellet mellem konfikser og affiksoider. Det første er, at det rent diakront er to forskellige processer. Konfikser stammer fra græske eller latinske rødder, som med tiden bruges som præfikser, der igen over en tid kan gå over til selvstændige rødder i andre sprog. Affiksoider er oprindelige rødder, der går over til at ligne affikser. Om de har en chance for at blive til affikser inden for en overskuelig tid, tvivler jeg på, fordi dette ville kræve, at rødderne, de stammer fra, skulle forsvinde. Jeg er klar over, at affikser i mange tilfælde stammer fra rødder, men det var en meget lang proces inden de blev til affikser. Mens konfikser beholder deres oprindelige betydninger, bliver betydningerne af de oprindelige rødder, der er ved blive affikser "degenereret" (jf. Jarvad, 1995:209). Konfikser kan til gengæld potentielt blive til frie rødder. Grafisk kan det vises på følgende måde:

Konfiks:

rod $>$ affiks $>$ rod

Affiksoid:

rod $>$ affiksoid $>$ ?affiks

Termen Konfix bruges først og fremmest i den tysksprogede litteratur, og i den engelsksprogede forekommer termen neoclassical compounds, og en term confix forekommer ikke, ikke en gang i værker som hos bl.a. Booij (2007), eller i Spencer/Zwickys Handbook of Morphology (1998).

Som det fremgår af oven stående, er forskerne ikke enige om definitionerne af de morfologiske enheder, der på nogen områder er meget produktive. Vanskeligheden med at definere sådanne enheder er stor, fordi sproget er "en levende organisme" og de enkelte sproglige enheder bruges forskelligt af forskellige sprogbrugere.

\section{3. ØKO- OG DETS BETYDNING OG BRUG I DANSK}

Morfemet $\varnothing k o$ - forekommer i de vigtigste danske opslagsværker som en orddannelsesenhed.

Efter Den Store Danske (DSD) er $\phi k o-$,

(1) græsk og internationalt forled, hvis anvendelse fremgår af to hovedeksempler: 1) økonomi, der opr. betegnede det at administrere sit eget hus og dets produktion, men nu bruges bredere om virksomhed, folk og regioner.

2) $\varnothing$ kologi, som betegner (læren om) levende væseners vekselvirkning med deres miljø. Adjektivet $\varnothing$ kologisk bruges især om varer produceret uden brug af gift- og tilsætningsstoffer, dvs. under hensyntagen til den opr. $\varnothing$ kologi.

I ord som $\varnothing$ kosystem er $\varnothing$ ko- kortform for $\varnothing$ kologi.

Forleddet $\varnothing$ ko- kommer af lat. oeco-, af gr. oikos 'hus, familie, husholdning, bolig, leveområde'. 
Dér kaldes morfemet $\phi k o$ - for et forled, men der angives ikke, om det drejer sig om et præfiks, eller en stamme, der kan være et led i komposita.

Den Danske Ordbog (DDO) betragter $\phi k o$ - som præfiks og definerer det således:

(2) Oprindelse i betydning 1 afkortning af $\emptyset$ kologisk, i betydning 2 afkortning af økonomisk

Betydninger

1. vedr. samspillet og balancen mellem levende organismer i naturen og mellem natur og mennesker

grammatik fx økologi, økosystem

1.a økologisk

grammatik især med substantiv som sidste led, fx økomad, økomælk

Salget af $\varnothing$ komælk ventes $\mathrm{i}$ år at vokse med op mod 26 mio. liter 2. vedr. fordeling af værdier og goder $\mathrm{i}$ en husholdning, en virksomhed, et land el.lign.

grammatik fx økohistorie, økonomi”

Hos Jarvad (1995:210 f.) hører $\phi k o$ - til kryptorødder, og kan efter hendes mening over tid gå over til en fri rod, der er ved at ske i forbindelse med dets høje produktivitet. Og hun anfører citater, der illustrerer brugen:

(3) Mærkaten 'grøn' eller ' $\varnothing \mathrm{ko}^{\prime}$ er ikke nogen garanti for noget som helst. Derimod bliver det ofte misbrugt i markedsføringen" (Politiken 8.6.1993),

og

(4) Når man siger 'øko' her i landet, tænker folk på begrebet økologi. (Politiken 13.6.1993).

Som det fremgår af oven stående beskrivelser af morfemet $\phi k o$, ligger oprindelsen i to ord, nemlig $\phi k o n o m i$ og $\phi k o l o g i$. Brugen af selve $\phi k o$ som første del i nydannede ord er betydningsmæssigt forbundet med ordet $\phi k o l o g i$ og ikke nødvendigvis фkonomi, hvilket antyder citater angivet af Jarvad (1995: $210 \mathrm{f}$.). Et andet eksempel, der bekræfter brugen af $\phi k o$ med betydningen, der henviser til фkologi, фkologisk er:

(5) Første professor i øko- økonomi: Vi kommer med et uønsket ... (Information 12.12.2012)

Der findes også brug som i фkoteknisk,

(6) adj. (1. led afkortelse af økonomi). det frie Universitet, Økoteknisk Højskole, hvis Formaal er at udføre et upolitisk Oplysningsarbejde om Samfunds$\varnothing$ konomien. Andelsbladet.1940.1606. Chr. Norlev. Økoteknisk Højskole. AvisKronikIndex.1940.325. (Supplement til ODS, 1992-2005) 
og фkometer / фkonometer som er dannet efter фkonomi og -meter, men det næste eksempel viser, at $\phi k o$ er mere forbundet med $\phi k o l o g i$ end $\phi k o n o m i$ :

(7) 12.12.2012 - Danmark har netop fået sin første professor i $\phi$ kologisk $\emptyset$ konomi. Nu mangler vi bare, at selve фkonomien også bliver grøn." (www.information.dk/319707)

Jeg vil i det følgende vise brugen af ord med $\not k o-$. I $D D O$ findes der 11 eksempler på ord med $\phi k o-$, og det er (bort set fra substantiver som $\phi k o l o g i$, $\phi k$ kologisk og $\phi k o l o g)$ substantiver: $\phi k o f r e a k, ~ \phi k o h i s t o r i e, ~ \phi k o l a n d b r u g$, фkologi, фkomad, фko-mad / фkomad, фkomalk, фkomarke, фkosystem,

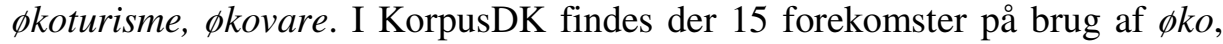
der står som et selvstændigt ord. Nogle af dem viser ikke helt brugen af morfemet, fordi de nogle gange som $\mathrm{i}$

(8) Dam Kristensen vil spørge det nye Forbrugerråd til råds om, hvor vidt Danmark skal have frivillig eller tvungen nationalitets-mærkning oven i de $\varnothing$ ko og kvalitetsmærker, vi allerede arbejder med. (Dagbladet Aktuelt 20.3.1997)

burde skrives sammen og ikke særskilt. I dette tilfælde burde det være " $\phi k o$ og kvalitetsmarker". I andre tilfælde står det for navne på firmaer som i:

(9) Hvis et ægteskab, hvori der har været formuefællesskab, ophører, og f.eks. du har haft en konto i et stormagasin eller en af kontoringene VEKO, ØKO eller lignende, og der iøvrigt ikke er nogen aktiver i fællesboet, så hæfter du og alene du for den pågældende konto." (Kvinde Dine rettigheder, år 83).

Som nævnt før er $\phi k o$ højproduktivt og der findes mange flere eksempler på brugen af dette morfem $\mathrm{i}$ internettet. Jeg vil her kun præsentere nogle eksempler på dem, fordi morfemet bruges meget og google.dk angiver ca. 7.280 .000 belæg. De bruges i tre skrivemåder: sammenskrivning, særskrivning og skrivning med bindestreg). Den første er sammenskrivning, som man skulle tro var den mest gængse, hvis man ser på eksemplerne fra Den Danske Ordbog, men det er ikke tilfældet. Sammenskrivningen gælder selvfølgelig først og fremmest belæg med $\phi k o l o g i, \phi k o l o g i s k$, og dannelser som фkocaféen (men: De fem фko caféer), фkodag, фkoinfo, $\phi k o-$ og konventionelle svin. Gruppen med særskrivning er repræsenteres af eksempler som: $\phi k o$ babyudstyr, $\phi k o$ creme, $\phi k o$ produkter, $\phi k o$ pyntekrave, $\phi k o$ shampoo, фko usigtet rugmel, фko sigtet rugmel, фko hvedemel, фko tørsur, $\phi k o$ solsikkekerner, $\phi k o$ h $\phi r f r \phi, \phi k o$ farvet malt. Den mest repræsenterede gruppe udgør dannelser skrevet med bindestreg, som f.eks. $\phi k o$-blyant, $\phi k o-b r u g, \phi k o-$ dag, фko-effektivitet, фko-gar, фko-gårdbutik, фko-innovation, фko-is, фko-kylling, $\phi k o-k \phi d, \phi k k-k \phi e r, \phi k o-l a n d m a n d, \phi k o-m a l k, \quad \phi k o-o p g a n g, \phi k o-o s t, \phi k o-$ restaurant, фko-skinke, фko-skønhedsprodukt, фko-tal, фko-tillag, фko-tur, фkoabler. 
Jeg vil ikke her påstå, at den ovenstående vurdering giver et fuldt billede af brugen, men jeg vil vove at hævde, at særskrivningen og skrivning med bindestreg er de mest udbredte stavemåder. Dertil kommer navne på firmaer, der skrives på alle tre måder, f.eks. Cat's Best Øko Plus kattegrus, Økokompaniet, Øko Kompaniet, Økokompaniet, Øko Ged og Grønt, Økokyllingen, $\emptyset$ ko-mystik, Øko-Energi.

Nedenunder følger eksempler på hjemmesider med brugen af $\phi k o-$, og som man kan se, er de fleste forekomster med bindestreg:

(10) a. Brødblandinger : Øko Solsikkerugbrød - Mejnerts (www.mejnerts.dk/.../oko-solsikkerugbrod-detaljer.ht...)

b. Øko-køerne skal på græs I Skiveportalen (www.skiveportalen.dk/showevent.jsp?id=482...5)

c. Øko-pumaen fra Mannheim I Berlingske Business (www.business.dk/global/oeko-pumaen-fra-mannheim)

d. Øko-Byg: Økologisk byggeri. (oekobyg.dk/)

e. Øko frugt \& grønt - Skagenfood (https://skagenfood.dk/da-dk/frugt.../oeko-frugt-groe...)

f. Øko-videnscenter - Det Økologiske Inspirationshus (www.byoko.dk/oekovidenscenter.asp)

g. Øko Best I Visitcopenhagen (www.visitcopenhagen.com/tellus-product/497898)

h. Tweets about \# $\varnothing$ ko hashtag on Twitter (https://twitter.com/hashtag/øko)

i. Babyolie ØKO - Urtegaarden (www.urtegaarden.dk $>\mathrm{Hjem}>$ Varer)

j. Første professor i $\varnothing$ ko- $\varnothing$ konomi: Vi kommer med et uønsket ... (www.information.dk/319707)

k. Tvedemose » Øko champignon (tvedemose.dk/produkter/oko-champignon)

1. Amphi Consult - Naturplaner og øko-mælk (amphi-consult.dk/projekter/naturplaner-og-oko-maelk)

m. Jürss: Svenske øko-oste | Artikler I Artikler - Gastro-Imports (www.gastro-import.dk/...juerss-svenske-oko-oste.ht...)

n. Her er de bedste $\varnothing$ ko-skønhedsprodukter lige nu - Alt for ... (www.altfordamerne.dk > Skønhed > Skønhed)

o. Øko-tur i Costa Rica - EF Danmark (www.ef-danmark.dk/lt/destinations/.../costa-rica-tour/)

\section{KONKLUSIONER}

$\emptyset k o$ som morfem klassificeres forskelligt, dvs. som præfiks, forled, kryptorod, og altså også konfiks. Morfemet stammer fra en græsk rod, der blev lånt og i lang tid opførte sig som et præfiks. Det kombineres ikke med affikser, 
men det kan godt kombineres med stammer og andre konfikser i større orddannelsesstrukturer. $\emptyset \mathrm{ko}$ forekommer mere og mere som et selvstændigt ord. Og når det sker, kan det betragtes som en forkortelse af adjektivet $\phi k o l o g i s k$ i f.eks. $\phi k o$ t $\phi j$, $\phi k o$ kylling, $\phi k o$ bilvask eller substantivet $\phi k o l o g i$ i f.eks.

(11) a. I LOVE ØKO - Hvad betyder økologi (www.iloveoko.dk/hvad/hvad-betyder-oekologi.aspx)

b. Er øko et sundere valg? - Sygeforsikringen "danmark" (www.sygeforsikring.dk/Default.aspx?ID=2094)

Man kunne også forestille sig en adverbial brug af $\not k o$, som i f.eks.

(12) Ingredienser: Øko usigtet rugmel, øko sigtet rugmel, $\varnothing \mathrm{ko}$ hvedemel, $\varnothing \mathrm{ko}$ tørsur ( $\varnothing \mathrm{ko} \mathrm{hvedemel,} \mathrm{starterkultur),} \mathrm{\varnothing ko} \mathrm{solsikkekerner,} \varnothing \mathrm{ko}$ hørfrø, salt, $\varnothing$ ko farvet malt. (Brødblandinger : Øko Solsikkerugbrød - Mejnerts www.mejnerts.dk/.../oko-solsikkerugbrod-detaljer.ht..)

Grunden til, at $\phi k o$ i de fleste tilfælde skrives særskilt eller med bindestreg kan være, at man ønsker at understrege vigtigheden af morfemet $\phi k o$, f.eks. af marketinggrunde. Ikke desto mindre bliver denne brug mere og mere udbredt, hvilket gør, at $\phi k o$ både morfologisk og semantisk begynder at fungere som et selvstændigt ord. Jeg vil her påstå, at den særskilte stavemåde ikke nødvendigvis skal betragtes som en stavefejl ved skrivningen af komposita, der efter normen skrives sammen, hvilket tit brydes $\mathrm{i}$ brugen efter påvirkningen fra engelsk. $\emptyset$ ko bruges i den slags tilfælde som et selvstændigt ord, og dette tyder også på, at $\phi k o$ er ved at blive til en selvstændig rod, eller måske allerede er blevet det.

Betydningen, $\phi k o$ bruges mest i, kommer fra $\phi k o l o g i$, som det fremgår af materialet ovenfor. Der er kun få forekomster på dannelser, jf. materialet ovenfor, som hentyder til фkonomi. Hvis man tager eksemplet $\emptyset$ kobil, så hentyder man til, at bilen kan køre mange kilometer på literen, og det er forbundet med omkostningerne af at køre den, men samtidig er det en $\emptyset$ kologisk bil, fordi den ikke udleder så meget udstødningsgas som biler, der kører færre kilometer på literen. Hvis man til gengæld vil udtrykke, at noget er

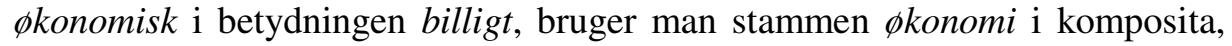
som i f.eks. фkonomiklasse, фkonomibil, фkonomipakke m.fl.

Morfemet $\phi k o$ bruges bl.a. som led i komposita, konfiksdannelser, og som et selvstændigt ord. Jeg vil derfor mene, at det nu kan betragtes som en rod i dansk. 


\section{LITTERATURHENVISNINGER}

Bauer, L. (1988). Introducing Linguistic Morphology. Edinburgh: Edinburgh University Press.

Booij, G. (2007). The Grammar of Words. An Introduction to Linguistic Morphology. $2^{\text {nd }}$ edition. Oxford: Oxford University Press.

Donalies, E. (1999). Können Wortbildungsaffixe semantische Kerne sein? Ein Diskussionsbeitrag zur Differenzierung der deutschen Affixe nach semantischen Kriterien. Deutsche Sprache 27, 195-208.

Donalies, E. (2000). Das Konfix. Zur Definition einer zentralen Einheit der deutschen Wortbildung. Deutsche Sprache 28, 144-159.

Eisenberg, P. (2004): Grundriss der deutschen Grammatik. Band 1: Das Wort. 2., überarb. und aktual. Aufl. Stuttgart: Metzler.

Elsen, H. (2005). Deutsche Konfixe. Deutsche Sprache 33, 133-40.

Fleischer, W., I. Barz (1995). Wortbildung der deutschen Gegenwartssprache. 2. durchgesehene und ergänzte Aufl. Tübingen: Max Niemeyer Verlag.

Spencer, A., Zwicky A. M. (eds.). (1998). The Handbook of Morphology. Oxford, Malden: Blackwell Publishers.

Høy, A. (1999). Hybrider og kryptorødder i medicinsk fagsprog - og de morfologiske og ortografiske udfordringer de afstedkommer. Nordterm 10. Nordterm '99. Schaffergården 13.-15. juni 1999, 47-57.

Jarvad, P. (1995): Nye ord - hvorfor og hvordan? København: Gyldendal.

Kocourek, R. (1982). La langue française de la technique et de la science. Wiesbaden: Brandstetter.

Müller, W. (1989). Die Beschreibung von Affixen und Affixoiden im allgemeinen einsprachigen Wörterbuch. In: F. J. Hausmann, Franz Joseph, O. Reichmann, H. E. Wiegang, L. Zgusta, (eds.): Wörterbücher / Dictionaries / Dictionnaires (s. 869-881). Berlin / New York: Walter de Gruyter.

Neef, M. (2009). IE, Germanic: German. In: R. Lieber, P. Štekauer (eds.). The Oxford Handbook of Compounding (s. 386-399). Oxford: Oxford University Press.

Rajnik, E. (2013). Substantivische Konfixe (Präkonfixe und Subkonfixe) und Konfixbildungen im Dänischen und Deutschen - Versuch einer Klassifikation. In: E. Błachut, J. Jarosz, A. Małgorzewicz, R. Opiłowski (eds.) SPRACHE - LITERATUR - KULTUR IM GERMANISTISCHEN GEFÜGE. Band 1: Sprachwissenschaft im Fokus germanistischer Forschung und Lehre (s. 423-431). Wrocław - Dresden: Neisse Verlag.

Rajnik, E. (2014). Substantiviske komplekse ord med subkonfikser i moderne dansk. Folia Scandinavica Posnaniensia 16, 41-49. DOI: 10.1515/fsp-2015-0003.

Scalise, S., Bisetto, A. (2009). The Classification of Compounds. In: R. Lieber, P. Štekauer (eds.), The Oxford Handbook of Compounding (s. 34-53). Oxford: Oxford University Press.

Schindler, J. (1997). Zur internen Syntax der indogermanischen Nominalkomposition. In: E. Crespo, J.L. García-Ramón (eds.). Berthold Delbrück y la sintaxis indoeuropea hoy. Actas del Coloqio de la Indogermanische Gesellschaft, Madrid, 21-24 septiembre de 1994 (537-40). Madrid/Wiesbaden: Ediciones de la Autönoma de Madrid/Reichert,.

Schmidt, G. D. (1987). Das Kombinem: Vorschläge zur Erweiterung des Begriffsfeldes und der Terminologie für den Bereich der Lehnwortbildung. In: G. Hoppe, A. Kirkness, E. Link, I. Nertmeyer, W. Rettig, G. D. Schmidt (eds.). Deutsche Lehnwortbildung. Beiträge zur Erforschung der Wortbildung mit entlehnten WB-Einheiten im Deutschen (37-52). Tübingen: Narr.

Schu, J. (2005). Zwischen Grundmorphem und Affix. Deutsche Sprache 33, 258-86.

Skolseg, E. (1997). Orddanningselementer i gråsona mellom frie og bundne morfemer. Ord om ord 3. Arsskrift for leksikografi 1997, 63-79.

Szubert, A. (2012). Zur internen Semantik der Nominalkomposita im Dänischen. Poznań: Wydawnictwo Naukowe UAM. 


\section{INTERNETKILDER}

$D S D=$ Den Store Danske. http://www.denstoredanske.dk (adgang den 17.06.2016)

$D D O=$ Den Danske Ordbog. http://ordnet.dk/ddo (adgang den 17.06.2016)

Korpus DK. http://ordnet.dk/ddo (adgang den 17.06.2016)

ODS = Ordbog over det danske Sprog. http://ordnet.dk/ods (adgang den 17.06.2016)

\section{Andrzej Szubert}

Uniwersytet im. Adama Mickiewicza w Poznaniu

Katedra Skandynawistyki

al. Niepodległości 4

61-874 Poznań

Poland

szubert@amu.edu.pl 